\title{
Closing the Circle: Research and Policymaking in Education
}

\author{
Simona Iftimescu, Georgeta Ion, Carmen Proteasa, Romiţă Iucu, \\ Elena Marin, and Mihaela Stîngu
}

\section{Introduction}

While the factors affecting the uptake of research findings in educational practice have been intensively analysed in the literature (Cain 2015 among others), few studies have focused on the field of policymaking, especially in countries with no strong tradition of using evidence in policymaking and those with a weaker research culture in public institutions. This study aims to address the factors contributing to research uptake in education policymaking, from the policymakers' perspective.

The existing literature points towards arguments supporting the role of research in policymaking (e.g. Temple 2003; Brown 2012) and the importance of research findings as a critical factor in any innovative change process in education (Levin et al. 2011). In addition, according to Oakley (2000:3), policymaking approaches involving the utilisation of research ensure that 'those who intervene in other people's lives do so with the utmost benefit and least harm'.

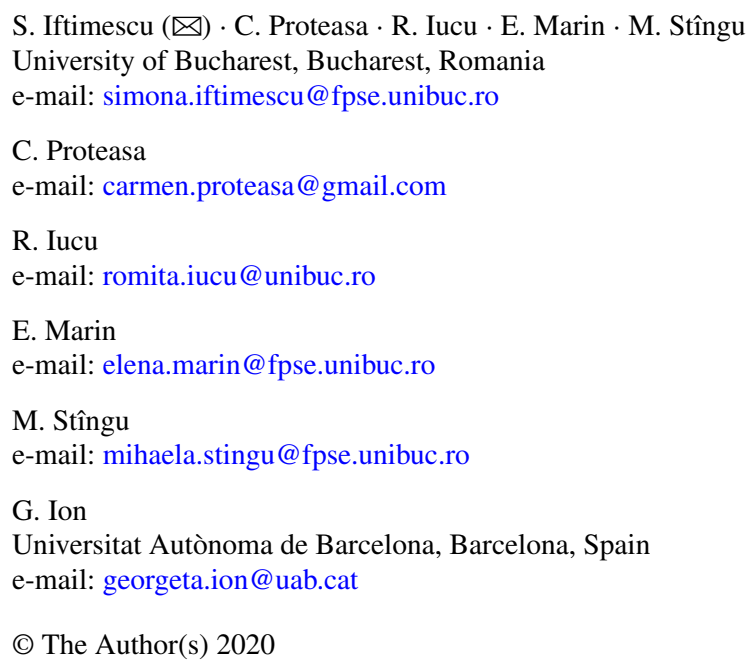


Evidence-based practice is a field that has already been explored in depth in health sciences and is now starting to be explored in other fields. For instance, Oxman (2009) point to the benefits of health systems with policymakers adopting an evidenceinformed approach, as systems that increase the probability of a more effective, equitable and efficient health policy. In contrast, the authors consider that "poorly informed decision-making is one of the reasons why services sometimes fail to reach those most in need (...) and may also contribute to problems related to the effectiveness, efficiency (i.e., value for money), and equity of health systems' (p. 1). Along the same lines, but in the field of education, the findings of Cordingley (2013) and Mincu (2014) suggest that using research in decision-making is associated with better teaching and learning, schools and systems. Tregenza et al. (2012) and Godfrey $(2014,2016)$ found similar relations. However, despite interest in the benefits of research-based approaches in policymaking and practice, 'little effort has gone into understanding how, when, or why research affects education policy', and 'most discussion has focused on how to identify $<$ best practices $>$ or $<$ scientifically based $>$ methods and how to encourage' the use of research findings (Hess and McDonnell 2008, p. 534).

There are many agents involved in the process of research utilisation (in the production process, but also in the use of research findings), and their alignment and its implications have been investigated. This analysis brings into focus some explanatory models, which encapsulate the variety of elements involved in these processes (Landry et al. 2001b; Levin 2013; Brown 2012 among others) and the role of human resources in supporting them. However, the complexity and the nature of the relationship between research producers and users prevent us from gaining a full and straightforward understanding of the process. While a significant body of literature explores the role of the research production context (among others Cherney et al. 2012) and the use of research in practice (among others Mincu 2015; Ostinelli 2017), studies exploring the complex context of policymakers are still underdeveloped in the educational field (among others Gough 2004; Lavis 2006; Cain 2015). For this reason, our research aims to contribute to the understanding of the factors involved in the uptake of research by educational policymakers, namely those involved in the national public administration. The study focuses on Romanian educational researchers in higher education institutions (as relevant producers of educational research influencing theoretical development, policy and practice, including in teaching and learning) and their relation to policymakers. Also, this is an exploratory study, which investigates perceptions on research in general, without differentiating amongst various methodologies and approaches to research (i.e. action research, fundamental research etc.). In this context, we first analyse the most common models explaining the factors influencing research utilisation. Second, we explore how these factors are shaped by civil servants in education in order to explore the emergence of other factors, and propose suggestions for how research-based policy processes might be more effectively supported by both researchers, in particular those in higher education, and policymakers. 


\section{Configuration of Factors Influencing the Research Uptake in Policymaking}

Definitions about evidence-informed policymaking (EIPM) have emerged in the literature in recent years and range from an approach which 'helps people make well informed decisions about policies, programmes and projects by putting the best available evidence at the heart of policy development and implementation' (Davies 1999:124), to understandings more associated with the concept of 'knowledge mobilization' (Cooper et al. 2009). The term describes the growing interest in studying the role that evidence plays in the policymaking process, which has been drawing interest for decades beyond the field of education.

However, there is little agreement about what the term EIPM really covers (Gough et al. 2011). The extent of what is considered 'evidence' is wide and can include expert knowledge, published research, statistics, stakeholder consultations, previous policy evaluations, other information sources and/or output from economic and statistical modelling. Thus, research is just one source amongst many (Nutley et al. 2007). To these elements, Wieser (2016) and Cain (2015) added both personal and professional experience in the construction of knowledge.

Independently of what shapes evidence-informed policymaking, the way evidence is configured depends on the articulation of different factors linked to individuals, groups and organisations (Ion and Iucu 2014). Many of these factors, which include political priorities, the availability of resources, contextual factors and information such as research, and other forms of evidence, play a direct role in the process of decision-making (e.g. Campbell et al. 2017; Davies 2004; Gough 2004; Nutley et al. 2007). Additionally, the relationship between evidence and decision-making is complex and involves not only different factors but also agents acting within various contexts. For example, in the evidence-informed policy and practice model, Levin (2013) proposes three contexts interfering in the utilisation of research: the context of the research production, mediators and research users. Levin (2013) and Tripney et al. (2015) conceptualise educational policymakers as 'end users' of research. Users function as constructors of knowledge and act in their own setting; they are not just passive recipients of the work of researchers (Levin 2009). In this context, we would argue that policymakers are a special case of mediators, who can potentially have a strong influence on ensuring that research findings are used in practice.

The literature has analysed different explanatory models for evidence-based policy and practice, integrating the different contexts mentioned before. Landry et al. (2001a) analysed different models in the literature, highlighting their potentials and limitations. The explanatory models of research utilisation cover a wide range of scenarios, and the authors discussed four major alternatives: the science-push model, the demand-pull model, the dissemination model and the interaction model. Each one addresses parts of the factors contributing to research use. Since we included some of the factors derived from these models in the research design of the present study, we will present a brief review of each one. 
The science-push model puts the emphasis on the role of the researchers and research in focusing on aspects such as the quality and type of research (basic/ applied, general/abstract, qualitative or qualitative, particular or concrete, etc.) and contends that the utilisation process follows a linear sequence from the supply of research findings to utilisation by policymakers and practitioners. The model has been criticised mainly due to two aspects: the transfer of knowledge is not automatic, and raw research information is not usable in policymaking. These aspects encouraged the emergence of the demand-pull model, which focuses on the role of the final users (policymakers and practitioners) in research utilisation. In this model, the users become the major source of ideas for policy initiatives (Weiss 1979; Rich 1991, among others). The demand-pull model assumes that organisational structures, rules and norms are essential determinants of knowledge utilisation (Oh and Rich 1996) and that the critical factor causing the under-utilisation of research findings links to the political interest of users, which may be in conflict with the research data (Landry et al. 2001a). Criticized for its excessive instrumental use of research and for the omission of the role of the interaction between users and knowledge producers, the model led to the emergence of the dissemination model, which described the role of the transfer process as both formal and non-formal. The dissemination model promoted the need to develop dissemination mechanisms to identify useful knowledge and transfer it to users. The model stresses the importance of two determinants: the type of research results and the dissemination effort (Landry et al. 2001a). The model's lack of attention to the process of dialogue between producers and users and to the gap between the two contexts prompted the appearance of the interaction model (among others Huberman and Thurler 1992; Oh 1997). The variables considered in this model are related to informal personal contacts, participation in committees and transmission of reports to non-academic organisations (Huberman and Thurler 1992).

Due to the recent progress in the field of knowledge utilisation, there has been some criticism associated to all existing models. For instance, Estabrooks et al. (2006) and Cooper et al. (2009) argue that the variables proposed in the models are not sufficient to explain the complexity and variety of the real situations, scenarios and agents involved in the research utilisation process.

To overcome the limitations of the previous models, Brown (2012) added variables derived from a sociological approach posited by Dowling (2008), known as the social activity model. The contribution of this model is the understanding of the knowledge adoption as 'most likely to occur when both researchers and policymakers are actively seeking to engage with one other, employing corresponding strategies to enable this process' (Brown 2012:460). This model and its criticisms led to a new configuration of the variables. The alternative is called the policy preference model (Brown 2012) and is centred on two points:

- factors directly related to the evidence and efforts to communicate this evidence;

- factors that impact how the findings from any study are likely to be received by its audience. 
From here, two categories of factors are derived (Brown 2012:460):

- internal factors: the nature of what is being communicated, clarity with regard to its presentation, the efficacy of the communication type and the level of proactivity, contextualisation and tailoring)

- external factors: factors inherent to policymakers and which constitute their knowledge 'mould', the perceived credibility of the source of evidence by policymakers, the perceived quality of the evidence by policymakers, general involvement by policymakers in research studies, and access to policymakers).

To these factors, Brown (2012) added factors linked to the preferences policymakers have for other research topics and the strength and nature of the relationship between the researcher and policymaker (Brown 2012).

\section{The Context of Our Study}

The connection between the different actors involved in educational public policy development is made through the Ministry of Education, working together with national institutions and agencies such as the Institute of Educational Sciences, the National Council for Curriculum and Evaluation, the National Centre for Evaluation and Examination, the National Centre for Vocational Education Development and the National Agencies for Quality Assurance in Education (higher education and pre-university education). The mechanisms for policy development in higher education are supported by the activity of the Ministry of Education, nine intermediary institutions, three national agencies, and 108 public and state universities.

The choice between different public policy alternatives needs to be supported by arguments based on studies and analyses, with clear information about the opportunity for addressing the issues concerned, the estimated budget, the estimated impact and evaluation criteria for each alternative, criteria for choosing the recommended alternative, and the related action plan. However, Romania is an example of a context where public policy is not coherently structured and regulated for utilising research to inform public policies. As a result, research uptake in policymaking is left at researchers' and policymakers' discretion.

In this study, we aim to detect and describe the configuration of the main factors that could influence the uptake of research for policymakers. Thus, our research explores the policymakers' perspective, placing it against the different explanatory models for evidence-based policy and practice.

\section{Methods}

The data comprised in this article are part of a project funded by the Ministry of Education through the Executive Unit for the Financing of Higher Education, Research, Development and Innovation, whose main objective is to analyse the utilisation of 
educational research in policymaking. The overall study (developed between 20152017) used a mixed methodology, comprising two surveys (one for policymakers and one for Romanian higher education academics and researchers), two sets of interviews with academic managers and with a selection of policymakers and governmental experts, as well as of a focus group with academics, university managers and policymakers. The current paper draws only on data gathered from the survey administered to policymakers working in public administration in the field of education.

\subsection{Survey Structure}

Research use was measured through 59 multiple-answer questions on a seven- to five-point scale, built on the policy preference model and its dimensions. These dimensions were considered as variables, related to internal factors linked to the quality and access to research data:

- the nature of what is being communicated

- the clarity in the presentation of research data

- access and availability of data

- factors linked to the preference of policymakers towards one or another research topic

- different sources of information

and external factors linked to the perceived relationship between policymakers and researchers:

- the perceived quality of the evidence by policymakers

- communication and dissemination

- the strength and nature of the relationship between researchers and policymakers

- policymakers' general involvement in research (i.e. agenda setting, collaboration with researchers, etc.)

In addition, two open-ended questions were added, related to:

- factors discouraging and encouraging policymakers to make educational policy decisions based on scientific evidence.

The independent variables used for this particular stage in the project are sociodemographic variables such as the respondents' role in the institution, overall professional experience, professional experience in their current position and the respondents' level of education, aiming to provide a better understanding of the context and particularities of research use at the decision-making level. The data analysis was carried out by clustering the survey questions around internal and external factors identified by the model. Then, data were analysed using the weightedvadjust average 
for each item correlated with the independent variables. For the limited purpose of this paper, we will focus on the respondents' institutional role in correlation with the above-mentioned internal and external factors.

\subsection{Sample}

The survey ${ }^{1}$ was administered in March 2017 to a self-selected sample of 54 civil servants from the main public institutions involved in the management of education in Romania. Most of the respondents $(70 \%)$ work at the Ministry of National Education (with $4 \%$ of them employed at the Strategy and Public Policy Unit within the Ministry), while 8\% work at the National Agency for Community Programmes for Education and Professional Development, 4\% at the Romanian Agency for Quality Assurance in Pre-University Education and 4\% at the Romanian Agency for Quality Assurance in Higher Education; 2\% work at the Executive Unit for the Financing of Higher Education, Research, Development and Innovation, and 12\% work in other public institutions in the educational field.

Out of those who responded to the survey, the majority $(40 \%)$ are experts in their field, while the rest are either in an administrative position (10\%), work at an executive level (26\%), have a research role (8\%), or are in charge of planning $(20 \%)$ and evaluation (12\%) of policies. As the overall total percentage shows (116\%), some respondents have, or identify with more than one role within their institution. All the respondents are considered to have a policymaker role, as they are involved, in different capacities, in formulating public educational policies within their particular institutional structure. The majority of the respondents have more than 10 years of experience in their current position (52\%), while $8 \%$ have worked in their current position for a period of time between 6 and 10 years, and $40 \%$ reported having worked for 1 to 5 years in their current capacity. Out of the total 54 respondents, all have higher education degrees, with $8.16 \%$ having completed a bachelor's degree, $51.02 \%$ a master's degree, $38.78 \%$ a Ph.D., while $2.04 \%$ preferred not to answer this specific question.

\section{Results}

The results of this study are presented in relation to the respondents' institutional role and follow the identified clusters: internal and external factors influencing the uptake of research by policymakers and factors encouraging or discouraging the policymakers to make educational policy decisions based on scientific evidence.

\footnotetext{
${ }^{1}$ The survey can be accessed at https://www.surveymonkey.com/r/3SXC225 (in Romanian).
} 


\subsection{Internal Factors Influencing the Uptake of Research by Policymakers}

When it comes to the internal factors influencing the uptake of research, we will focus on the policymakers' perceptions on the nature and clarity of communication, access and availability of data, on factors linked to their preferences for research topics, and on the different sources of information they use.

With regard to the nature of what is being communicated, respondents appear to focus on the practical and applied side of research (M: 4.78/6). Respondents also place high value on clarity in the presentation of what is being communicated, as research results written in a clear language for decision-makers represent one of the factors receiving higher consideration (M: 4.56/6). The availability of results when a decision has to be made also appears to be an important factor influencing research use (M: 4.62/6), an aspect that encourages more communication and synchronicity between research and decision-making agendas in order to ensure research is relevant to current issues and readily available for decision-makers (Table 1).

With regards to access and availability of data, there are several outliers that could be further discussed. First, it appears the administrative staff tend to agree that the current methods of knowledge dissemination derived from educational research seem adequate (M: 5.00/6), even though they are least exposed to research results and usage while, by comparison, those more directly involved with research are more reserved on this (an overall average of $\mathrm{M}$ : 4.09/6). This is also reflected in the fact that administrative staff agree that the institution they work with has specific structures

Table 1 When you want to use results of academic educational research, which aspects do you consider a priority? (on a scale from 1 to 6 , where 1 represents 'low priority' and 6 represents 'high priority')

\begin{tabular}{l|l|l|l|l|l}
\hline $\begin{array}{l}\text { Statement Role } \\
\text { within the institution }\end{array}$ & $\begin{array}{l}\text { Results with } \\
\text { direct } \\
\text { implications } \\
\text { on policies } \\
\text { and } \\
\text { practices are } \\
\text { a priority }\end{array}$ & $\begin{array}{l}\text { The results } \\
\text { being } \\
\text { readily } \\
\text { available } \\
\text { when a } \\
\text { decision has } \\
\text { to be made } \\
\text { is a priority }\end{array}$ & $\begin{array}{l}\text { Research } \\
\text { results } \\
\text { written in a } \\
\text { clear } \\
\text { language for } \\
\text { decision- } \\
\text { makers are a } \\
\text { priority }\end{array}$ & $\begin{array}{l}\text { Research } \\
\text { which } \\
\text { contributes } \\
\text { to the } \\
\text { existing } \\
\text { theoretical } \\
\text { knowledge } \\
\text { is a priority }\end{array}$ & $\begin{array}{l}\text { Impartial } \\
\text { results of the } \\
\text { research are } \\
\text { a priority }\end{array}$ \\
\hline Administrative & 5 & 4.8 & 4.8 & 4 & 4.2 \\
\hline Expert in a certain field & 4.65 & 4.5 & 4.58 & 4.2 & 4.7 \\
\hline Executive & 4.85 & 4.69 & 4.54 & 4.54 & 4.46 \\
\hline $\begin{array}{l}\text { Documentation/ } \\
\text { research }\end{array}$ & 5 & 4.75 & 4.75 & 4.5 & 3.5 \\
\hline Planning & 4.4 & 4.5 & 4.4 & 4.3 & 4 \\
\hline Evaluation & 4.83 & 4.5 & 4.33 & 4.17 & 3.67 \\
\hline Rating average & $\mathbf{4 . 7 8}$ & $\mathbf{4 . 6 2}$ & $\mathbf{4 . 5 6}$ & $\mathbf{4 . 2 8}$ & $\mathbf{4 . 0 8}$ \\
\hline
\end{tabular}


Table 2 Please indicate your level of agreement with each of the following statements (on a scale from 1 to 6, where 1 represents 'complete disagreement' and 6 represents 'complete agreement'

\begin{tabular}{l|l|l|l|l|l}
\hline $\begin{array}{l}\text { Statement role } \\
\text { within the institution }\end{array}$ & $\begin{array}{l}\text { Technology } \\
\text { has greatly } \\
\text { improved } \\
\text { access to } \\
\text { scientific } \\
\text { evidence }\end{array}$ & $\begin{array}{l}\text { Academic } \\
\text { research is } \\
\text { independent } \\
\text { from the } \\
\text { political } \\
\text { agenda }\end{array}$ & $\begin{array}{l}\text { I often use } \\
\text { research } \\
\text { evidence } \\
\text { when I } \\
\text { formulate/ } \\
\text { initiate/ } \\
\text { evaluate an } \\
\text { educational } \\
\text { policy } \\
\text { initiative }\end{array}$ & $\begin{array}{l}\text { The current } \\
\text { models of } \\
\text { knowledge } \\
\text { dissemina- } \\
\text { tion derived } \\
\text { from } \\
\text { educational } \\
\text { research } \\
\text { seem } \\
\text { adequate to } \\
\text { me }\end{array}$ & $\begin{array}{l}\text { The } \\
\text { available } \\
\text { resources } \\
\text { are sufficient } \\
\text { so that we } \\
\text { can use } \\
\text { research } \\
\text { data }\end{array}$ \\
\hline Administrative & 5.20 & 4.6 & 4.20 & 5 & 4 \\
\hline Expert in a certain field & 5.37 & 4.5 & 4.70 & 3.8 & 2.75 \\
\hline Executive & 5.67 & 5 & 4.15 & 3.75 & 2.77 \\
\hline $\begin{array}{l}\text { Documentation/ } \\
\text { research }\end{array}$ & 5.50 & 5 & 4.00 & 3.5 & 3.25 \\
\hline Planning & 5.50 & 4.4 & 4.40 & 4.2 & 3 \\
\hline Evaluation & 5.67 & 4 & 4.67 & 4.33 & 2.5 \\
\hline Rating average & $\mathbf{5 . 4 8}$ & $\mathbf{4 . 5 8}$ & $\mathbf{4 . 3 5}$ & $\mathbf{4 . 0 9}$ & $\mathbf{3 . 0 4}$ \\
\hline
\end{tabular}

that allow access and usage of scientific data, an opinion shared by their colleagues to a lesser extent, as shown in Table 2.

However, the majority of respondents disagree with the fact that the available resources are sufficient for them to use research data (M: 3.04/6), which might be a reason why research evidence is not always used when formulating, initiating or evaluating an educational policy initiative (M: 4.35/6).

With regards to the different sources of information used by policymakers, the majority of respondents agree that technology has significantly improved access to scientific evidence (M: 5.48/6), and the most relevant sources appear to be national and international statistical databases (M: 5.14/6) and national agencies' reports (M: 4.92/6) as shown in Table 3. This indicates that policymakers are more familiar with institutional reports and raw data issued by national or international organizations and not by researchers in higher education. It is worth noting that respondents rely heavily on their previous professional experience (M: 5.03/6), thus underlining the contribution of experiential learning to the development of professional knowledge and the need for them to be more involved in the research process in order to expand and use their knowledge in the field, which also draws upon external factors.

The researchers' proactivity is reflected in policymakers receiving results of research carried out by higher education institutions or research centres, and it indicates a more direct connection between researchers and policymakers primarily at the executive level (M: 4.55/6) and to a lesser extent among experts (M: 4.16/6). Those policymakers who tend to read and analyse research reports are mostly execu- 


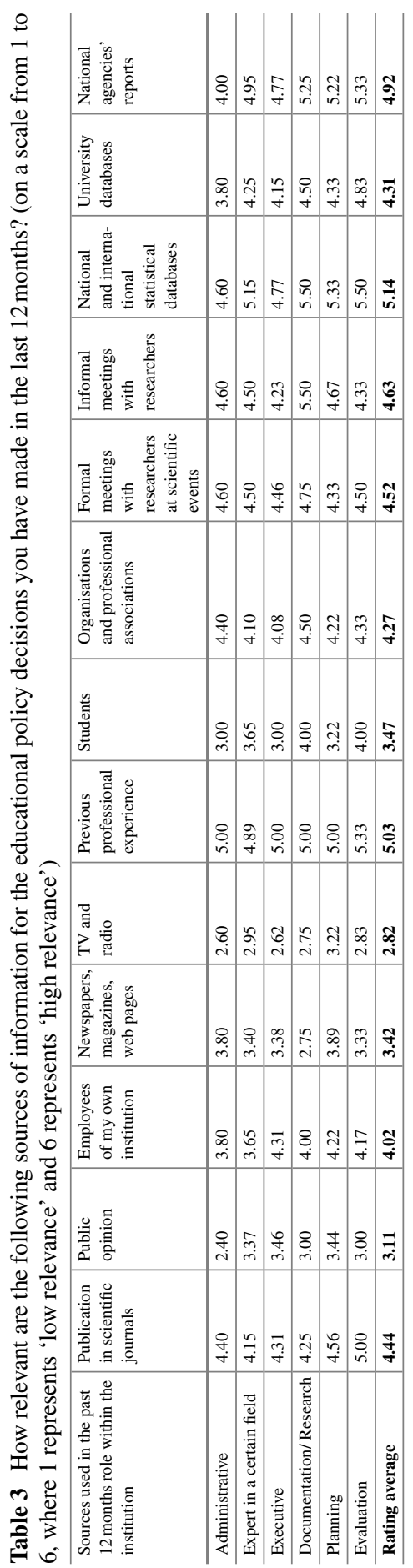


Table 4 When you access and use educational research in decision-making, how frequently do you encounter the following situations? (on a scale from 1 to 6 , where 1 represents 'never' and 6 represents 'always')

\begin{tabular}{|c|c|c|c|c|}
\hline $\begin{array}{l}\text { Situations in which } \\
\text { research data were used } \\
\text { role within the institution }\end{array}$ & $\begin{array}{l}\text { Educational } \\
\text { research has } \\
\text { been used to } \\
\text { project and } \\
\text { implement } \\
\text { educational } \\
\text { policies and } \\
\text { programs }\end{array}$ & $\begin{array}{l}\text { Educational } \\
\text { research has } \\
\text { been used to } \\
\text { influence the } \\
\text { way in which } \\
\text { decision- } \\
\text { makers reflect } \\
\text { upon different } \\
\text { educational } \\
\text { aspects }\end{array}$ & $\begin{array}{l}\text { Educational } \\
\text { research has } \\
\text { been used to } \\
\text { introduce new } \\
\text { aspects on the } \\
\text { political agenda }\end{array}$ & $\begin{array}{l}\text { Educational } \\
\text { research has } \\
\text { been used to } \\
\text { justify or } \\
\text { legitimize } \\
\text { options already } \\
\text { chosen by the } \\
\text { decision- } \\
\text { makers }\end{array}$ \\
\hline Administrative & 4.40 & 3.80 & 3.60 & 3.75 \\
\hline Expert in a certain field & 4.00 & 3.47 & 3.26 & 3.67 \\
\hline Executive & 4.15 & 4.08 & 3.38 & 3.36 \\
\hline Documentation/research & 4.00 & 3.75 & 3.75 & 4.50 \\
\hline Planning & 4.00 & 3.70 & 3.50 & 3.89 \\
\hline Evaluation & 4.00 & 3.33 & 3.33 & 3.00 \\
\hline Rating average & 4.09 & 3.68 & 3.47 & 3.69 \\
\hline
\end{tabular}

tives (M: 5.45/6) and those working in evaluation (M: 5.50/6). Whereas the latter are less likely to receive results directly from researchers (M: 3.67/6), they appear to use research more in their work; therefore, they should be among those targeted in the dissemination process. When referring to policymakers' proactivity towards research use, the lowest overall rating average is recorded for respondents feeling encouraged by their colleagues/peers to use research data in their activity (M: 3.82/6), which reflects a rather low value attributed to organisational factors in relation to research use.

With regard to contextualization and tailoring of research for policymakers, the results show that respondents most frequently see educational research being used in order to plan or project and implement educational policies and programmes (M: 4.09/6). A lower average (M: 3.68/6) is reported for educational research used to influence the way decision-makers reflect upon different educational aspects. The trend is consistent with educational research being used to introduce new aspects on the policy agenda (M: 3.47/6) and to justify or legitimize options or decisions already made by decision-makers (M: 3.69/6), an aspect which is more aligned with the demand-pull model, as previously described.

Values reflected in Table 4 indicate a rather limited role of research in relation to the policy agenda, as perceived by the majority of respondents, with the lowest weighted averages reported by respondents involved in evaluation at the institutional level. It could also be inferred from comparing data that, while all respondents recognize the importance of research and research use in decision-making, in reality, the connection between the two components appears to be rather weak. 


\subsection{External Factors Associated with the Uptake of Research in Policymaking}

In this section, we will focus on two external factors identified in relation to the perceived relationship between policymakers and researchers: policymakers' general involvement in research studies and the strength and nature of the relationship between researchers, particularly in higher education, and policymakers.

Policymakers' general involvement in research studies refers mostly to reading and analysing research reports (M: 5.31/6) and to adopting results of educational research (M: 5.56/6), two aspects relevant mostly for those in executive and policy evaluation roles at the institutional level. However, there is a high level of agreement regarding the lack of training in the field of research utilisation within public institutions where decisions are made (M: 4.06/6), indicating the need for such training in supporting and encouraging the use of research in policymaking.

An important aspect would also be to increase access to policymakers, considered to be relatively low given the lack of sufficient forums and networks that could bring together researchers in higher education institutions (HEIs) and policymakers $(3.96 / 6)$. This is also reflected in a rather low average of policymakers receiving results of research carried out by universities or research centres (M: 3.87/6). A stronger collaboration between policymakers and researchers in higher education is further deterred by the amount of time that must be invested in coordinating the activity between the two parties (M: 4.42/6) and the existing bureaucratic practices, which can cause delays (M: 4.26/6).

Following up on these aspects, it would appear that the strength and nature of the relationship between researchers in higher education and policymakers are influenced by the rather limited access to policymakers as well as by the different agendas and timeframes for research and for decision-making.

However, the results presented in Table 5 indicate partnerships with universities are highly regarded by policymakers, who see such partnerships as playing a motivational and commitment role, as research partnerships appear to motivate some of the respondents to further engage with their own work (M: 3.83/5) and to extend the number of contacts with universities (M: 3.78/5). Moreover, there appears to be a general openness towards working in projects developed in collaboration with HEIs and strengthening the relationship between policymakers and researchers in higher education.

The qualitative data collected at the end of the survey summarises the main enablers, facilitators and inhibitors of the uptake of research by policymakers. In aspects related to communication and dissemination of research results, respondents value using a clear and friendly language for 'translating results in common language' and expect researchers to make their work more visible and be more proactive in connecting and communicating with policymakers. They also suggest developing partnerships with influential factors within civil society and organisations working in European educational programmes. With regard to the research content, policymakers recommend clear, easy-to-understand proposals with short-term impact adapted 


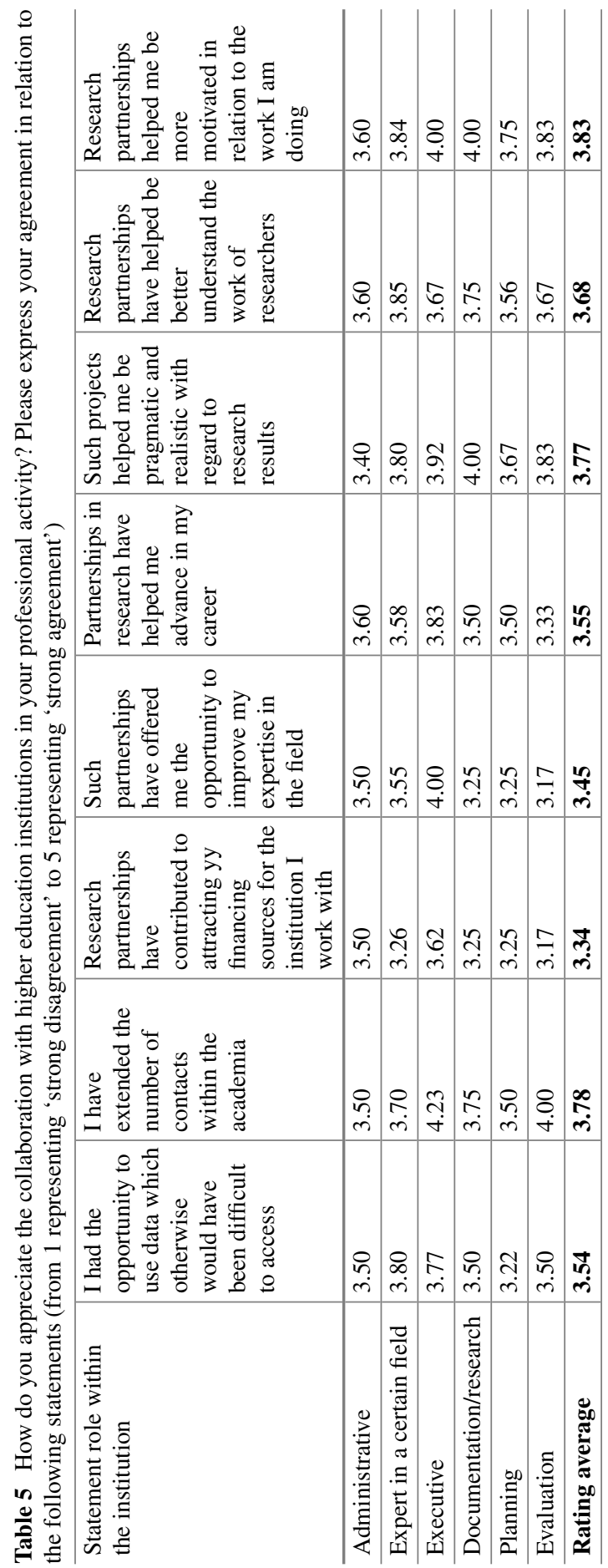


to the context and to the specific requirements of the environment where they will be implemented. They also expect researchers to be more proactive and participate as experts in implementing projects developed by institutions that initiate educational policies.

The factors that encourage policymakers to make educational policy decisions based on scientific evidence vary from personal factors (intrinsic motivation), such as their personal desire to improve their expertise or their professional responsibility, to results-driven factors (extrinsic motivation), either in relation to the decision-makers, such the possibility to influence decisions or substantiate pertinent argumentation that could help adopt a policy, or in relation to the system, such as obtaining long-term positive results and ensuring objectivity in making decisions. Furthermore, there are factors pertaining to existing general evidence, particularly the decreasing quality of the educational process or the increase in the drop-out rate, as well as factors related to research, namely the need to access highly accurate data, based on rigorous and realistic research, objectivity and sample representativeness.

Besides, the factors discouraging policymakers from making educational policy decisions based on scientific evidence are identified at either systemic or institutional levels or are determined by factors related to research itself. Regarding the latter, barriers appear mainly in relation to the lack of correlation between theory and practice and the risk of over-theorization, as well as access to evidence. At the systemic level, respondents are concerned by public sphere inertia, lack of coherence in designing strategies, the numerous changes in the system, and the lack of thematic research in the national context which is needed when promoting educational policies measures. At the institutional level, the main concerns refer to the lack of institutional or practical culture in using results of research and innovation in practice as well as at the level of decision-making. One observation that could be made with regard to this aspect refers to the actual and perceived identity of the policymaker. Given the current data and the wider context of the research, it appears that employees in public administration, even though in charge of drafting, implementing and evaluating policies, do not necessarily perceive themselves as decision-makers, a role which they mostly attribute to elected or appointed officials in their field. This could also fall under the external factors influencing the research uptake, namely, under factors linked to the preferences of policymakers for one or another research topic, which indicate their preference is mostly driven by the decision-making agenda and less by particular topics of interest. Thus, their preferences appear to be highly volatile and influenced by the political factor, making it difficult for researchers to respond promptly to their requests, especially given the different timeframes in the research cycle and the political decision cycle. 


\section{Discussion}

Our study analysed the factors linked to the perception of policymakers on the use of research in their work. The findings demonstrated that, despite the weak presence of national regulations regarding the support of evidence-based decisions in education, policymakers highly value research contributions and agree that research makes them more confident in their decisions and has implications on the quality of their work. The data also reveal that their trust in educational research is a critical factor in understanding the dynamic of research uptake in policymaking and is the criteria for a successful relationship between researchers and policymakers. In this regard, our results confirm the findings of previous studies (e.g. Brown et al. 2016). However, in a context where research appears mostly as part of political discourse of elected officials and less as an actual practice for civil servants, policymakers still consider their own professional experience as an important source of knowledge when decisions are made. The least relevant aspect in terms of key factors for considering research of priority appears to be the use of research which contributes to the existing theoretical knowledge. This situation generates a discussion about knowledge management in public administration and the balance between formal and informal mechanisms to access evidence. It also sparks a debate on the partnerships and alliances between those in charge of knowledge production and those who use it (Treadway 2015).

The findings shed light on the role of personal and organisational factors in influencing the research utilisation as an organisational dynamic with its internal structures, while also highlighting the role of the existing research culture at public institutions. The research culture is a critical aspect and is linked to the group dynamic in a given organisation (Ion and Iucu 2014), and the support of colleagues and leaders. Similarly, our data highlight the importance of training policymakers in order to increase their level of awareness in the use of data derived from research. The findings also spark discussion, not only on the various internal and external factors contributing to the research uptake, but also on the role played by civil servants in their institutions. Depending on their responsibilities, they could be more or less connected to research.

As it can be inferred from the findings, educational research in Romania is currently at a crossroad between the science-push model, as higher education institutions are attempting to influence the research agenda required for evidence-based policymaking and disseminate their results, and the demand-pull model, as policymakers are trying to design evidence-based policies without always being able to find the necessary evidence, and with policy interests not necessarily in line with research interests at higher education institutions - who are the main research producers. Even more so, the demand-pull model sometimes implies that the policymakers are looking at evidence to justify their decisions afterwards rather than inform them beforehand, which creates an even larger rift between the two parties.

The study suggests a number of implications for policymakers in public administration. Our research paves the way for an in-depth analysis of organisational factors likely to affect research utilisation: engagement, interpreted as the attitude of organ- 
isations and their members towards research; the political and managerial context likely to promote and favour research transfer and use; and the financial context needed to foster quality results. Thus, there is a growing need to enhance the partnerships between policymakers and researchers (Malin and Brown 2019), focusing on high-quality research, well-developed transparency and social responsibility mechanisms, as well the 'third mission' as an academic priority.

Whereas the study tackles the idea of bridging the gap between the policymakers' and researchers' contexts, it cannot provide, at this stage, a full understanding of how an efficient partnership could be defined. However, it provides us with a sense of the policymakers' positive perception regarding the collaboration with researchers in higher education institutions, and it points to possible directions for the latter to strengthen this relation. Researchers could be more proactive in disseminating research results, specifically in engaging with executive and policy evaluation staff in public institutions. Also, more opportunities for researchers and policymakers to meet in both formal and informal contexts could contribute to such engagement from both parties. Another recommendation would be to develop initial and continuous training programs aimed at interpreting and understanding research results, at applying them in drafting educational policy or at facilitating research utilisation in public institutions. It could also contribute to better prepared graduates as future, better informed research producers, users and mediators, and to shaping a clearer role for research in an overall strategy to develop the higher education system.

Acknowledgements The paper derives from a research project funded by the Romanian National Authority for Scientific Research and Innovation, CNCS-UEFISCDI, project number PN-II-RUTE-2014-4-1605.

\section{References}

Brown, C. (2012). The Policy-Preferences Model: A New Perspective on How Researchers Can Facilitate the Take-up of Evidence by Educational Policy Makers. The Policy Press, 8(4), 455-72.

Brown, C., Daly, A., \& Liou, Y. (2016). Improving Trust, Improving Schools. Journal of Professional Capital and Community, 1(1), 69-91. Emerald Group Publishing Limited. doi:https://doi.org/10. 1108/JPCC-09-2015-0004.

Cain, T. (2015). Teachers' Engagement with Research Texts: Beyond Instrumental, Conceptual or Strategic Use. Journal of Education for Teaching, 41(5), 478-92. https://doi.org/10.1080/ 02607476.2015.1105536.

Campbell, C., Pollock, K., Briscoe, P., Carr-Harris, S., \& Tuters, S. (2017). Developing a knowledge network for applied education research to mobilise evidence in and for educational practice. Educational Research, 59(2), 209-227. https://doi.org/10.1080/00131881.2017.1310364.

Cherney, A., Povey, J., Head, B., Boreham, P., \& Ferguson, M. (2012). What Influences the Utilisation of Educational Research by Policy-Makers and Practitioners? The Perspectives of Academic Educational Researchers. International Journal of Educational Research. Elsevier Ltd. doi:https://doi.org/10.1016/j.ijer.2012.08.001.

Cooper, A., Levin, B, \& Campbell, C. (2009). The Growing (but Still Limited) Importance of Evidence in Education Policy and Practice. Journal of Educational Change, 10(2-3), 159-71. https://doi.org/10.1007/s10833-009-9107-0. 
Cordingley, P. (2013). The Contribution of Research to Teachers' Professional Learning and Development. Research and Teacher Education: The BERA-RSA Inquiry, 1-13.

Davies, P. (1999). What Is Evidence-Based Education?British Journal of Educational Studies, 47(2), 108-21. Taylor \& Francis Group. https://doi.org/10.1111/1467-8527.00106.

Davies, P. (2004). Is evidence-based government possible? Jerry Lee Lecture, presented at the 4th Annual Campbell Collaboration Colloquium, Washington DC.

Dowling, P. (2008). Unit 4: Generating a research question. In Research and the Theoretical Field Lecture Pack and Reading Pack London: University of London.

Estabrooks, C.A., Thompson, D.S., Lovely, J.J.E., \& Hofmeyer, A. (2006). A Guide to Knowledge Translation Theory. Journal of Continuing Education in the Health Professions, 26(1), 25-36. https://doi.org/10.1002/chp.48.

Godfrey, D. (2014). Creating a Research Culture - Lessons from Other Schools. The Voice for Secondary Education, 21 March http://www.sec-ed.co.uk/best-practice/creating-a-researchculture-lessons-from-other-schools.

Godfrey, D. (2016). Leadership of Schools as Research-Led Organisations in the English Educational Environment. Educational Management Administration \& Leadership 44 (2): 301-21. https://doi.org/10.1177/1741143213508294.

Gough, D. (2004). Systematic Research Synthesis. In G. Thomas \& R. Pring Evidence-Based Practice in Education. Open University Press.

Gough, D., Tripney, J., Kenny, C., \& Buk-Berge, E. (2011). Evidence Informed Policymaking in Education in Europe. EIPEE Final Project Report Summary. http://www.eipee.eu/.

Hess, F. M., \& McDonnell, L. (2008). When Research Matters: How Scholarship Influences Education Policy. Cambridge Mass.: Harvard Education Press. http://www.worldcat.org/ title/when-research-matters-how-scholarship-influences-educational-policy/oclc/495194314\& referer=brief_results.

Huberman, M., \&Thurler, G. (1992). De La Recherche À La Pratique. Eléments de Base. Revue Française de Pédagogie, 98(1), 69-82. Persée - Portail des revues scientifiques en SHS. https:// doi.org/10.3406/rfp.1992.1335.

Ion, G.,\& Iucu, R. (2014). Does Research Influence Educational Policy? The Perspective of Researchers and Policy-Makers in Romania. In A. Curaj, L. Matei, R. Pricopie, J. Salmi, \& P. Scott (Eds.), The European Higher Education Area: Between Critical Reflections and Future Policies, (pp. 873-89). London: Springer.

Landry, R., Amara, N., \& Lamari, M. (2001a). Climbing the Ladder of Research Utilization: Evidence from Social Science Research. Science Communication. https://doi.org/10.1177/ 1075547001022004003.

Landry, R., Amara, N., \& Lamari, M. (2001b). Utilization of Social Science Research Knowledge in Canada. Research Policy, 30(2), 333-49. https://doi.org/10.1016/S0048-7333(00)00081-0.

Lavis, J. N. (2006). Research, Public Policymaking, and Knowledge-Translation Processes: Canadian Efforts to Build Bridges. Journal of Continuing Education in the Health Professions, 26(1). Wiley Subscription Services, Inc., A Wiley Company: 37-45. doi:https://doi.org/10.1002/chp. 49.

Levin, B. (2009). How Governments Decide: The Role of Research. Research of $v s$ Research for Education Policy: In an Era of Transnational Policy-Making, edited by Richard Desjardins and Kjell Rubenson, 210. Saarbrucken: VDM Verlag Dr. Muller. http://www.worldcat.org/title/research-of-vs-research-for-education-policy-in-an-eraof-transnational-policy-making/oclc/527526759\&referer=brief_results.

Levin, B. (2013). To Know Is Not Enough: Research Knowledge and Its Use. Review of Education, 1(1), 2-31. https://doi.org/10.1002/rev3.3001.

Levin, B., Cooper, A., Arjomand, S., \& Thompson, K. (2011). Can Simple Interventions Increase Research Use in Secondary Schools? Canadian Journal of Educational Administration and Policy December (126), 1-29. http://files.eric.ed.gov/fulltext/EJ955449.pdf.

Malin, J., \& Brown, C. (2019). The Role of Knowledge Brokers in Education: Connecting the Dots Between Research and Practice. London: Routledge. 
Mincu, M. (2014). Building Collective Capacity for Improvement at a School and System Level. British Educational Research Association, 5, 1-36. http://www.voced.edu.au/content/ngv60343.

Mincu, M. (2015). Teacher Quality and School Improvement: What Is the Role of Research? Oxford Review of Education, 41(2), 253-69. https://doi.org/10.1080/03054985.2015.1023013.

Nutley, S., Walter, I., \& Davies, H. (2007). Using Evidence: How Research Can Inform Public Services. Policy Press, 363. http://press.uchicago.edu/ucp/books/book/distributed/U/bo13441009. html.

Oakley, A. (2000). Experiments in Knowing: Gender and Method in the Social Sciences. New York: New Press.

Oh, C. H. (1997). Issues for the New Thinking of Knowledge Utilization: Introductory Remarks. Knowledge and Policy,10(3), 3-10. Springer Netherlands. https://doi.org/10.1007/BF02912503.

Oh, C. H., \& Rich, R. (1996). Explaining Use of Information in Public Policymaking. Knowledge and Policy, 9(1), 3-35. Springer Netherlands. https://doi.org/10.1007/BF02832231.

Ostinelli, G. (2017). Between University and School: The School Improvement Advisor/researcher (SIA). International Journal of Leadership in Education, 22(2), 189-205. 3124 (August). Routledge: $1-17$. https://doi.org/10.1080/13603124.2017.1321784.

Oxman, A. D., Lavis, J.N., Lewin, S., \& Fretheim, A. (2009). SUPPORT Tools for evidenceinformed health Policymaking (STP) 1: What is evidence-informed policymaking? Health Research Policy and Systems, 7, 1-7. https://doi.org/10.1186/1478-4505-7-S1-S1.

Rich, R. (1991). Knowledge Creation, Diffusion, and Utilization. Knowledge, 12(3). Sage Publications Sage CA: Thousand Oaks, CA: 319-37. https://doi.org/10.1177/107554709101200308.

Temple, P. (2003). Educational Research and Policymaking: Findings from Some Transitional Countries. London Review of Education, 1(3), 217-228. https://doi.org/10.1080/ 1474846032000146776.

Treadway, C. (2015). 'Policymakers' Perceptions on the Application of Research Evidence in the Policymaking Process within West Virginia's Higher Education System‘. Theses, Dissertations and Capstones. 945. https://mds.marshall.edu/etd/945

Tregenza, J., Sebba, J., \& Kent, P. (2012). Powerful Professional Learning: A School Leader. A Guide to Joint Practice Development: Nottingham.

Tripney, J., Kenny, C.,\& Gough, D. (2015). Enabling the Use of Research Evidence Within Educational Policymaking in Europe Enabling the Use of Research Evidence Within Educational Policymaking in Europe Lessons from the EIPEE Project 4934 (October). doi:https://doi.org/10. 2753/EUE1056-4934460103.

Weiss, C. H. (1979). The Many Meanings of Research Utilisation. Public Administration Review,39(5), Wiley American Society for Public Administration: 426. doi:https://doi.org/10. 2307/3109916.

Wieser, C. (2016). Teaching and Personal Educational Knowledge - Conceptual Considerations for Research on Knowledge Transformation. European Journal of Teacher Education, 39(5), 588-601. https://doi.org/10.1080/02619768.2016.1253673.

Open Access This chapter is licensed under the terms of the Creative Commons Attribution 4.0 International License (http://creativecommons.org/licenses/by/4.0/), which permits use, sharing, adaptation, distribution and reproduction in any medium or format, as long as you give appropriate credit to the original author(s) and the source, provide a link to the Creative Commons license and indicate if changes were made.

The images or other third party material in this chapter are included in the chapter's Creative Commons license, unless indicated otherwise in a credit line to the material. If material is not included in the chapter's Creative Commons license and your intended use is not permitted by statutory regulation or exceeds the permitted use, you will need to obtain permission directly from the copyright holder.

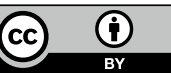

